dr hab. Ewa ROSZKOWSKA, prof. UwB

Faculty of Economics and Management, University of Bialystok

e-mail: erosz@o2.pl

DOI: $10.15290 /$ ose.2016.02.80.11

\title{
THE APPLICATION OF UTA METHOD FOR SUPPORT EVALUATION NEGOTIATION OFFERS ${ }^{1}$
}

\begin{abstract}
Summary
The MCDA technique has been extensively and successfully applied for supporting decision making in negotiation processes. The mostly used techniques SAW, AHP or TOPSIS are based on direct preference information which requires from negotiator a clear and precise definition all the parameters of the preference model (e.g. issue weights, option rates, aspiration and reservation values etc.), so those techniques can be successfully applied in well-structured negotiation problems. But, many real negotiation problems are illstructured, that means that the negotiation space is imprecisely defined, and the negotiator's preferences the vagueness or imperfect.

The main purpose of this paper is to investigate the potentials and the applicability the UTA method, one of the techniques based on indirect preference information, in evaluation of negotiation offers, especially in ill-structured negotiation problems. The UTA (Jacquet-Lagreze and Siskos, 1978, 1982, 2001) is a multicriteria decision making method which is based on the linear programming model for inferring additive utility functions from a set of representative decision data. The example is also presented to elaborate and demonstrate the holistic judgment and the usefulness UTA approach for evaluation negotiation offers.
\end{abstract}

Key words: UTA method, holistic judgments, support negotiation, preference analysis, scoring function

JEL: C02, C30

\section{Introduction}

Various MCDM techniques have already been applied for solving the evaluation negotiation offers problems [see Salo, Hamalainen, 2010; Brzostowski et al. 2012a, 2012b; Wachowicz et al. 2012; Wachowicz, Błaszczyk 2012; Roszkowska et al. 2012, 2014, 2015a, b; Górecka et al. 2014, 2016]. The scoring system can be determined by simply additive weighting method (SAW), [Kersten, Noronha, 1999; Schoop et al. 2003] which is used, for instance, in such negotiation support systems as Inspire or Negoisst. Another technique is AHP [Saaty 1980] which is applied in Web-HIPRE system [Mustajoki, Hamalainen, 2000; Kersten, Lai, 2007; Brzostowski, Roszkowska, 2012a]. In series of papers [Roszkowska et al. 2012, 2014, 2015a, 2016; Wachowicz, Błaszczyk

\footnotetext{
${ }^{1}$ This research was supported by the grant from Polish National Science Centre (2015/17/B/HS4/00941).
} 
2014] the technique for order preference by similarity to ideal solution (TOPSIS) method was also discussed in the perspective of evaluation negotiation offers.

In general, the negotiator can construct scoring system taking into account direct or indirect preference information provided by him [Greco et al. 2008; Figueira et al. 2009]. The direct preference elicitation requires from negotiator a clear and precise definition of all the parameters of the preference model (e.g. issue weights, option rates, aspiration and reservation values etc.), whereas the indirect preference information requires selected examples/negotiation offers which are used to inducing the parameters of the preference model and all the remaining packages considered within the decision making problem may be evaluated and rank. The direct preference information is used in the traditional aggregation paradigm, according to which the aggregation model is first constructed and then applied on set $X$ to rank the alternatives, so for instance in SAW, AHP or TOPSIS algorithm. Indirect preference information is used in the disaggregation (or regression) paradigm, according to which the holistic preferences on a subset of alternatives $R \subseteq X$ are known first, and then a consistent aggregation model is inferred from this information to be applied on set $X$ in order to rank the alternatives [Greco et al. 2008, Figueira et al. 2009, Siskos et al. 2001, Kadziński et al. 2012; Ishizaka and Nemery 2013].

Summing up, the multi-criteria techniques based on direct preference information can be applied mainly in well-structured negotiation problems. However, most real negotiation decision problems take place in a complex environment where conflicting systems of criteria, uncertain and imprecise knowledge, and possibly vague or imperfect preferences have to be considered. To face such complexity and ill-structure of negotiation problems, the use of specific tools, techniques, and concepts which allow the available information to be represented is necessary.

In this paper we are particularly interested in the role of indirect preference information based on relatively less cognitive negotiator's effort and holistic judgment in multi-criteria techniques which can be apply in ill-structured negotiation problems for evaluation negotiation offers.

The holistic judgment approach in evaluation negotiation offers were considered previously in some papers. In the paper [Górecka et al. 2014] a new algorithm for eliciting the negotiators' preferences in multi-issue negotiations that hybridize the basic concepts of ZAPROS and MACBETH was proposed. This algorithm requires of the negotiators to compare the reference alternatives that differ from the ideal one in the resolution level of one issue only (the ZAPROS-like approach). Also, in the papers [Roszkowska, Wachowicz, 2015b], two technique MARS and GRIP based on holistic judgment, were discuss in the context to support negotiation problems.

In this paper however, we propose an effective application of holistic judgment and disaggregation paradigm which is apply in the UTA (UTilités Additives) approach and UTA software to handle indirect preference information in ill-structured negotiation problems. More exactly, we proposed an application of the UTA method to determining scoring functions for the evaluation of negotiation offers. The UTA method JacquetLagreze, Siskos, 1982] is based on preference disaggregation model and aims to assess decision models from a priori known decision or preference data in the form of ranked lists of options. At the first step decision maker describe a set of criteria with non-decreasing, 
exhaustive and non-redundant utility functions. Next, using special linear programming techniques, one global and several partial additive utility functions are obtained from a given ranking of the reference set options. At the end a stability analysis check is included, as a post-optimization step. The UTA method adopt the aggregation-disaggregation approach which constitutes a basis for the interaction between the analyst and the DM, which includes the consistency between the assessed preference model and the a priori preferences of the $\mathrm{DM}$, and he overall evaluation of potential actions [Siskos et al. 2005; Ishizaka, Nemery 2013].

The UTA-based methods have been applied in several real-world decision-making problems in the fields of venture capital evaluation, portfolio selection and management, failure prediction, business financing country risk assessment marketing of new products, marketing of agricultural products, consumer behavior customer satisfaction, sales strategy problems, job evaluation, among many others [for more review see Siskos et al. 2005].

Despite the UTA approach has already been considered in the literature with many applications there is no research on applying it to the support of the ill-structured negotiation problems. The main contribution of the paper is the discussion about applicability of holistic judgment and UTA technique as well preference disaggregation analysis in negotiation problems, and its efficiency.

The paper is organized as follows. Section 2 outlines the basic features, mathematical formulation and operation of the UTA method. The negotiation scoring system based on UTA approach is presented in Section 3. The example using UTA software is discussed in Section 4. Finally, Section 5 concludes the article, summarizes the main findings of this research and proposes some future research directions.

\section{The fundaments of UTA method}

The UTA (UTilités Additives) method was proposed by Jacquet-Lagreze and Siskos $[1978,1982]$ to aim at inferring one or more additive value functions from a given ranking on reference set. This technique is based on MAUT, adopt the preference disaggregation principle and uses linear programming techniques in order to optimally infer additive value/utility functions which are as consistent as possible with the global decisionmaker's preferences. The UTA algorithm have been improved and extended for various applications therefore resulting in a family of UTA methods. Several variants of the UTA method incorporate, for instance, different forms of optimality criteria used in the LP formulation, are developed. For an overview of UTA family methods [see Siskos et al. 2005; Siskos et al. 2001; Figueira et al. 2009; Greco et al. 2008; Kadziński et al. 2012].

The UTA is one of the multi-criteria decision making technique which is based on Multi-attribute Utility Theory (MAUT) and assess additive value functions on the whole criteria. We have two main preferences approaches: traditional aggregation paradigm as well disaggregation-aggregation (or regression) paradigm. In the aggregation approach the criteria aggregation model is first constructed and then applied on set A to get 
information about the comprehensive preference. Contrary to the disaggregation-aggregation model where the comprehensive preference on a subset is known a priori (but the global preference is unknown) and a consistent criteria aggregation model is inferred from this information [Greco et al. 2007; Figueira et al. 2009; Ishizaka, Nemery, 2013]

In UTA technique the preference disaggregation approach refers to the analysis (disaggregation) of the global preferences (judgment policy) of the DM in order to identify the criteria aggregation model that underlies the preference result.

Let us assume that we have multi-criteria decision-making problem, where the decision maker considers a set of alternatives, called $A$, which is valued by a family of criteria $F=\left\{f_{1}, f_{2}, \ldots, f_{j}, \ldots, f_{n}\right\}$.

Let us use the following notation:

- $\mathrm{A}=\left\{a_{1}, a_{2}, \ldots, a_{i}, \ldots, a_{m}\right\}$ is finite set of alternatives,

- $\quad \mathrm{R}$ - reference set

- $F=\left\{f_{1}, f_{2}, \ldots, f_{j}, \ldots, f_{n}\right\}$ is finite set of criteria,

- $\mathrm{f}_{j}\left(a_{i}\right)$ is the evaluation of the alternative $a_{i}$ on criterion $\mathrm{f}_{j}, i \in\{1,2, . . \mathrm{n}\}$,

- $\quad X_{j}$ - domain of criterion $f_{j}, X=\prod_{i=1}^{n} X_{i}$ the evaluation space,

- $\left[f_{i^{*}}, f_{i}^{*}\right]$ the interval of criterion evaluation scale $f_{i^{*}}<f_{i}^{*}, i \in\{1,2, . \mathrm{n}\}$,

- $\quad u_{j}$ are non-decreasing real marginal value function, $j \in\{1,2, . . \mathrm{n}\}$,

- $\quad U(x)$ - the global utility function.

The aim of the UTA method [acquet-Lagreze and Siskos 1982] is to infer the marginal utility functions of $U$ through the ordinal ranking given by the decision maker on the reference set $R \subseteq A$. The preference information is given in the form of a complete preorder on a subset of reference alternatives $R \subseteq A$, called reference preorder. A decision maker (DM) is willing to rank the alternatives in $R$ from the best to the worst, according to his/her preferences. The goal is to construct such an additive utility function $U$ which reflect to decision maker's preferences. The UTA methods used an unweighted form of additive value function, where for each $x \in X$,

$$
U(x)=\sum_{j=1}^{n} u_{j}\left(f_{j}(x)\right)=\sum_{j=1}^{n} u_{j}(x),
$$

where

$u_{j}$ are non-decreasing real marginal value functions,

$$
u_{j}: F_{j} \rightarrow R \text { for } \mathrm{i}-1, \ldots, \mathrm{n}
$$

satisfying normalization constrains:

$$
\sum_{j=1}^{n} u_{j}\left(f_{i}^{*}\right)=1
$$


and

$$
u_{j}\left(f_{i^{*}}\right)=0 \text { for } i=1,2, \ldots, n
$$

where: $\left[f_{i^{*}}, f_{i}^{*}\right]$ - interval values for criterion $f_{i}$.

The UTA marginal value functions $u_{j}$ are assumed to be piecewise linear. This requires the analyst or decision maker to define the number of endpoints for each criterion. When a criterion accepts only discrete scores, this parameter can also correspond to the number of possible values for this criterion. This 'endpoints' allows to determined unknown marginal utility scores by the linear program. For each criterion, the interval $\left[f_{i^{*}}, f_{i}^{*}\right]$ is divided into $\alpha_{\mathrm{i}}-1$ equal sub-intervals, so that end points $f_{i}^{j}$ are given by the formula:

$$
f_{i}^{j}=\mathrm{f}_{\mathrm{i}^{*}}+\frac{(j-1)}{\alpha_{i}-1}\left(f_{i}^{*}-\mathrm{f}_{\mathrm{i}^{*}}\right)
$$

for $j=1,2, \ldots, \alpha_{\mathrm{i}}$.

If the marginal utility scores of these endpoints are known, the utility score of any point $\mathrm{f}_{\mathrm{i}}(\mathrm{x}) \in\left[f_{i}^{j} ; f_{i}^{j+1}\right]$ is calculated in the following way:

$$
u_{i}\left(f_{i}^{j}(x)\right)=u_{i}\left(\mathrm{f}_{\mathrm{i}}^{\mathrm{j}}\right)+\frac{\left(\mathrm{f}_{\mathrm{i}}(\mathrm{x})-\mathrm{f}_{i}\right)}{\mathrm{f}_{\mathrm{i}}^{j+1}-\mathrm{f}_{\mathrm{i}}^{\mathrm{j}}}\left(u_{i}\left(f_{i}^{j+1}\right)-u_{i}\left(f_{i}^{j}\right)\right)
$$

for $j=1,2, \ldots, \alpha_{\mathrm{i}}$

The decision maker needs to provide a complete ranking on the reference (learning) set $R$ which avoids any incomparability amongst alternatives. For all the alternatives of the learning set $R$, the approximate marginal utility function can be calculated and next the marginal value function are finally estimated by means of the linear program [for details see: Siskos et al 2005]. The stability analysis of the results provided by LP is considered as a post-optimality analysis problem. Thus, we can obtain utility function by solving linear problem task minimizing sum of estimation errors, under constraints that provides enforced properties of the additive utility function.

The additive global utility function $U$ has following properties: normalized values of utility, for worst evaluation equals 0 , while the total utility for the best evaluations equals 1 ; concordance of preferences defined by decision maker's on the $\mathrm{R}$ set, preferences monotonicity for each defined criterion, minimal utility estimation error (defined as sum of gathered estimation errors).

Each alternative of set $X$ is evaluated on the basis of function $U$ and receives a 'utility score' $U(a)$ which allows the ranking of all alternatives from best to worst. The preference and indifference relations amongst the alternatives of $X$ are thus defined as follows:

$$
\begin{gathered}
\text { for every } a, b \in X a \mathbf{P} b \Leftrightarrow U(a)>U(b): a \text { is preferred to } b, \\
\text { for every } a, b \in X: a \mathbf{I} b \Leftrightarrow U(a)=U(b): a \text { and } b \text { are indifferent. }
\end{gathered}
$$

Each alternative of set $X$ is evaluated on the basis of function $U$ and receives a 'utility score' $U(a)$ which allows the ranking of all alternatives from best to worst. 


\section{The evaluation negotiation offers using UTA procedure}

In the prenegotiation phase the negotiation template is evaluated and the negotiation offer scoring system is built to support negotiators in their decisions [Raiffa, 1982]. Negotiation template describes the structure of the negotiation problem in the form of defined list of issues and feasible options of these issues [Raiffa et al. 2002]. In the case of big negotiation problems or continuous options the wide ranges of options are reduced to salient options only to discretize the negotiation problem and make it easier to analyze. The evaluated template is used to support the negotiators in evaluating the offers, analyzing the negotiation progress, scale of concessions among many others [Roszkowska, Wachowicz, 2015b].

To formalize the model of negotiation template and building scoring function we start with the following definitions:

- a negotiation package (option) is an offer, which negotiator may send to or receive from their opponent,

- $\quad$ an issue is a criterion negotiator use to evaluate the offers.

Let us denote by:

- $F=\left(f_{1}, f_{2}, \ldots, f_{n}\right)$, the set of negotiation issues,

- $\quad X_{i}=\left\{x_{i}^{j}\right\}_{j=1, \ldots,\left|X_{i}\right|}$ the sets of feasible resolution levels (options) for each issue $f_{i}$,

- $\quad X=\prod_{i=1}^{n} X_{i}$ the set of all feasible negotiation offers (packages)

- $\quad x=\left(x_{1}, x_{2}, \ldots, x_{n}\right)$, where $x \in X$ is a vector of options which represents negotiation package.

The negotiation offer scoring systems, is determined by a set of non-decreasing marginal value functions $u_{i}: X_{i} \rightarrow \mathrm{R}$, for $i=1, \ldots, \mathrm{n}$ that allow to assign scores $u_{i}\left(x_{i}^{j}\right)$ to each option defined in the negotiation template and evaluate each negotiation offer $x \in X$ by means of additive value function

$$
U(x)=\sum_{i=1}^{n} u_{i}\left(x_{i}\right) .
$$

We assume here, that according to the general assumptions of additive preference aggregation the DM's preferences over the resolution levels are mutually preference independent. The UTA procedure of indirect eliciting preferences and building the negotiation offer scoring systems consists of the steps (see Schema 1). 
SCHEMA 1. The process of building negotiation offer scoring system based on UTA approach

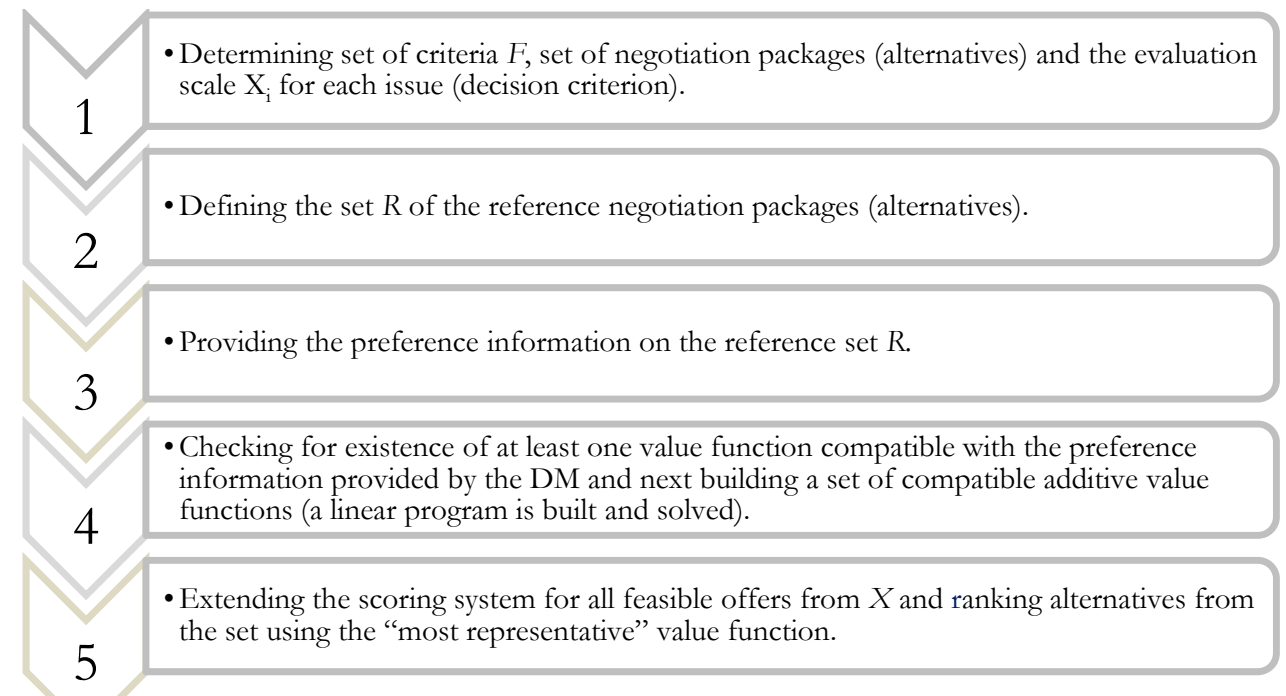

Source: own elaboration.

We describe her more exactly all steps:

Step 1. Determining set of criteria $F$, set of negotiation packages (alternatives) and the evaluation scale for each issue (decision criterion) $X_{i}$.

The negotiation template is a simplified definition of the negotiation space and specifies the set of negotiation issues and the sets of feasible resolution levels (options) for each issue. Three different types of criteria in UTA software can be used: cost (less is better), gain (more is better) and ordinal (non numerical criterion in view of classified negotiation offers).Two first types of criteria can be used especially in the case of quantities issues, and the ordinal scale in case qualitative issues. It is word noting that the ordinal scale can be also represented easy by linguistic labels.

Step 2. Defining the set $R$ of the reference negotiation packages (alternatives) from the set $X$.

From the total set of packages $X$ to be evaluated, a small number is selected as a reference set $R$. The set of the reference alternatives consists of those packages for which negotiator's judgment is certain and preference information is easy to obtain. Alternatively, a set of virtual offers whose values on the criteria are assigned deliberately can be constructed by the negotiator to aid the decision making his global evaluation (ranking). The offers 
composing the reference set have to be: at first known to the evaluators, in order to facilitate the negotiator in expressing her/his overall evaluation (ranking) as well representative of the whole set of offers, in order to take into account the different levels of the decision space, covering its whole range. From this point of view in this work we can recommend the following reference sets, based on ZAPROS approach [Larichev, Moshkovich, 1995, 1997; Moshkovich et al. 2005]:

- $\quad \mathrm{R}=Y_{\text {nIRS }} \cup\left\{\mathrm{P}_{I}\right\}$, where $Y_{\text {nIRS }}$ is the set of all hypothetical negotiation packages with the best evaluation for all the criteria but one, so it is a set of packages being near to the Ideal Reference Situation, $P_{I}$ - the ideal package, that's means package with the best evaluation for all the criteria

- $R=Y_{\text {nAIRS }} \cup P_{A I}$, where $Y_{\text {nAIRS }}$ is the set of all hypothetical negotiation packages with the worst evaluation for all the criteria but one, so it is a set of alternatives being near to the Anti-Ideal Reference Situation, $P_{A I}$ - the anti-ideal package, that's means package with the worst evaluation for all the criteria.

It is worth nothing that set $R$ is used in MARS procedure [Górecka et al. 2014, 2016]. The advantages of UTA approach is fact that the preference information is collected in a very easy way and concerns a small subset of negotiations offers and playing the role of a training sample. Elicitation of holistic pairwise comparisons the negotiation packages from Reference Set require from the negotiator relatively small cognitive effort. From the perspective of negotiator the set represent the offers which are near the Ideal Reference Situation, so those which can be easy accept by him. On the other way the set with offers closed the Anti-Ideal Reference Situation represent offers which are definitely reject by negotiator.

Step 3. Providing the preference information on the reference set $R$

The preference information describes a preference relation on a set of reference alternatives from $R$, e.g. "alternative $\boldsymbol{a}$ is at least as good as $\boldsymbol{b}$ ". In the UTA software the weak order, defined on the subset of alternatives have to be introduced by negotiator. The UTA technique does not require to evaluate the weights of issues separately, but derives them from package-to-package comparisons. It is especially comfortable in negotiations situations, where it is very difficult for him/her to elicit exactly criteria weights. The process involved to assess an overall preference using a decomposed analytical procedure may be not natural to him. The negotiator can say only that one criterion is more important that the other, but most aggregation methods require a more precise information, so negotiator might reject any model based on weights which are less meaningful to him. On the other hand, especially when some offers are known he can more easily compare these all packages in a holistic manner. "Offer $\boldsymbol{a}$ is better than $\boldsymbol{b}$ ". Taking this into account, UTA technique allow negotiator to evaluate trade-offs by comparing complete packages, so seems more natural for negotiators since it is close to the actual decision making analysis conducted in a real-life negotiation [Roszkowska, Wachowicz, 2015]. 
Step 4. Checking for existence of at least one value function compatible with the preference information provided by the DM and next building a set of compatible additive value functions (a linear program is built and solved).

In this steep the non-decreasing marginal value functions for each issues are constructed which allow to assign scores to each option defined in the negotiation template. Next all packages can be evaluate by means of additive value function. The number of linear pieces of marginal utility function used to model its marginal utility value should be introduced in UTA software by negotiator. As result we obtain the marginal utility function diagrams for every criterion and the rank of alternatives evaluated by these utility functions. The final ranking describing ordered alternatives with calculated comprehensive utilities for every alternative is also given.

What is important the UTA software allow modify value of the marginal utility function within the range of for a given criterion in characteristic points. The scope of possible modifications, assuming the unchanged value of Kendall coefficient calculated for the initial solution. Modifying in such scope the values of marginal utility function in characteristic points we can estimate the robustness of obtained rank in relation to the values of marginal utility for a given criterion. Of course, negotiator can modify more deeply the marginal utility function values in characteristic point what can result in changes of initially obtained rank of alternatives ${ }^{2}$

Step 5. Extending the scoring system for all feasible offers from $X$ and ranking alternatives from the set using the "most representative" value function.

\section{Illustrative example and discussion}

In this section, we present the numerical example to illustrate application holistic judgment in evaluation negotiation packages. We testify practically all steps of negotiator preference analysis to show usefulness UTA approach. Let as assume that Seller and Buyer negotiate the conditions of the potential business contract.

The following negotiation issues are discussed:

$f_{1}-$ unitary price (EUR),

$f_{2}$ - time of delivery (days),

$f_{3}$ - time of payment (days).

The negotiation template is defined by the numerical value for all criteria

- $\quad$ Price (EUR): $\langle 20,40\rangle$ for both parties;

- $\quad$ Time of delivery (days): $\langle 3,30\rangle$ for both parties,

- $\quad$ Time of payment (days): $\langle 3,21\rangle$ for both parties.

To build the initial set of packages in the pre-negotiation phase Seller defines the salient options for each issue in the following way:

\footnotetext{
2 See description Visual UTA method in Visual UTA software available at: http://idss.cs.put.poznan.pl/ site/visualuta.htm (date of access: 05.05.2015).
} 
- $\quad$ Price: $20,30,40$.

- $\quad$ Time of delivery: 3 (days), 7 (days), 14 (days), 30 (days),

- $\quad$ Time of payment: 3 (days), 14 (days), 21 (days).

The scoring system for the feasible negotiation offers can be created out of various combinations of the salient options $(3 \times 4 \times 3=36$ different packages). Since we assume that the Buyer considers $f_{1}, f_{2}$ to be the cost issue, and $f_{3}$, to be the benefit one. The Ideal Reference Vector has the form W(20,3,21), and the Anti-Ideal Reference Vector is the following: $\mathrm{W}(40,30,3)$.

Having such defined negotiation template Seller implemented VISUAL UTA software to elicit the preferences and generate the scoring system of the negotiation offers. We will testify three different Reference sets.

Reference Set 1. Let us assume that the buyer would like to compare offers with the Ideal Reference Vector W $(20,3,21)$ and is able to evaluate the options by declaring the occurrence of preferences (one option is better than another). The reference set $R S_{1}$ consists of all hypothetical negotiation packages with the best evaluation for all the criteria but one so the set of packages being near to the Ideal Reference Situation and the Ideal Reference Vector. The reference set has the form: $\operatorname{RS}_{1}=\{\mathrm{W}(20,3,21), \mathrm{W}(20,3,14)$, W(20,7,21), W(20,14,21), W(30,3,21), W(20,30,21), W(20,3,3), W(40,3,21)\}.

Reference Set 2: Let us assume that the buyer would like to compare offers with the Anty-Ideal Reference Vector W(40,30,3) and is able to evaluate the options by declaring the occurrence of preferences (one option is better than another). The reference set $R S_{2}$ consists of the set of all hypothetical negotiation packages with the best evaluation for all the criteria but one, so the set of packages being near to the Ideal Reference Situation and the Anty-Ideal Reference Vector The reference set has the form: $\mathrm{RS}_{2}=\{\mathrm{W}(20,30,3)$, W(30,30,3), W(40,3,3), W(40,7,3), W(40,14,3), W(40,30,21), W(40,30,14), W(40,30,3)\}.

Reference Set 3: consists of those packages for which negotiator's judgment preference information was easy to obtain. The reference set has the form: $\mathrm{RS}_{3}=\{\mathrm{W}(20,30,3)$, W(40,30,21), W(40,30,14), W(40,3,3), W(40,7,3), W(30,30,3)\}.

The rankordering packages from considered reference sets are presented in Table 1.

TABLE 1.

The rankordering packages for Reference Sets

\begin{tabular}{|c|l|l|l|}
\hline Range & \multicolumn{1}{|c|}{$\begin{array}{c}\text { Reference Set 1 } \\
\left(\mathbf{R S}_{\mathbf{1}}\right)\end{array}$} & \multicolumn{1}{|c|}{$\begin{array}{c}\text { Reference Set 2 } \\
\mathbf{( R S}_{\mathbf{2}}\end{array}$} & $\begin{array}{c}\text { Reference Set 3 } \\
\left.\mathbf{( R S}_{\mathbf{3}}\right)\end{array}$ \\
\hline 1 & $\mathrm{~W}(20,3,21)$ & $\mathrm{W}(20,30,3)$ & $\mathrm{W}(20,30,3)$ \\
2 & $\mathrm{~W}(20,3,14)$ & $\mathrm{W}(30,30,3)$ & $\mathrm{W}(40,30,21)$ \\
3 & $\mathrm{~W}(20,7,21)$ & $\mathrm{W}(40,3,3)$ & $\mathrm{W}(40,30,14)$ \\
4 & $\mathrm{~W}(20,14,21)$ & $\mathrm{W}(40,7,3)$ & $\mathrm{W}(40,3,3)$ \\
5 & $\mathrm{~W}(30,3,21)$ & $\mathrm{W}(40,14,3)$ & $\mathrm{W}(40,7,3)$ \\
6 & $\mathrm{~W}(20,30,21)$ & $\mathrm{W}(40,30,21)$ & $\mathrm{W}(30,30,3)$ \\
7 & $\mathrm{~W}(20,3,3)$ & $\mathrm{W}(40,30,14)$ & \\
\hline 8 & $\mathrm{~W}(40,3,21)$ & $\mathrm{W}(40,30,3)$ & \\
\hline
\end{tabular}

Source: own elaboration. 
As result $\mathrm{UTA}^{3}$ software we obtain the marginal utility function for every criterion and reference set as well the rank of alternatives evaluated by these utility functions. The results illustrating the piecewise linear marginal utility function for the criterion Price, Time of delivery and Payment are given in the tables 2-4 and Schemas 2-4

TABLE 2.

Marginal utility function for criterion „Price”

\begin{tabular}{|c|c|c|c|}
\hline Value & $\begin{array}{c}\text { Reference Set } 1 \\
\left(\mathrm{RS}_{1}\right)\end{array}$ & $\begin{array}{c}\text { Reference Set } 2 \\
\left(\mathrm{RS}_{2}\right)\end{array}$ & $\begin{array}{c}\text { Reference Set } 3 \\
\left(\mathrm{RS}_{3}\right)\end{array}$ \\
\hline 20 & 0,343333 & 0,5 & 0,428571 \\
\hline 30 & 0,288333 & 0,444444 & 0,071429 \\
\hline 40 & 0 & 0 & 0 \\
\hline
\end{tabular}

Source: own elaboration using VisualUTA software.

TABLE 3.

Marginal utility function for criterion „Time of delivery”

\begin{tabular}{|c|c|c|c|}
\hline Value & $\begin{array}{l}\text { Reference Set } 1 \\
\left(\mathrm{RS}_{1}\right)\end{array}$ & $\begin{array}{l}\text { Reference Set } 2 \\
\left(\mathrm{RS}_{2}\right)\end{array}$ & $\begin{array}{c}\text { Reference Set } 3 \\
\left(\mathrm{RS}_{3}\right)\end{array}$ \\
\hline 3 & 0,323333 & 0,388889 & 0,214286 \\
\hline 12 & 0,278333 & 0,166667 & 0,053571 \\
\hline 21 & 0,278333 & 0,166667 & 0,053571 \\
\hline 30 & 0 & 0 & 0 \\
\hline
\end{tabular}

Source: own elaboration using VisualUTA software.

TABLE 4.

Marginal utility function for criterion „Payment”

\begin{tabular}{|c|c|c|c|}
\hline Value & $\begin{array}{l}\text { Reference Set } 1 \\
\left(\mathrm{RS}_{1}\right)\end{array}$ & $\begin{array}{c}\text { Reference Set } 2 \\
\left(\mathrm{RS}_{2}\right)\end{array}$ & $\begin{array}{c}\text { Reference Set } 3 \\
\left(\mathrm{RS}_{3}\right)\end{array}$ \\
\hline 3 & 0 & 0 & 0 \\
\hline 12 & 0,320476 & 0,039683 & 0,265306 \\
\hline 21 & 0,333333 & 0,111111 & 0,357143 \\
\hline
\end{tabular}

Source: own elaboration using VisualUTA software.

The final ranking describing ordered negotiation packages with calculated scoring points (comprehensive utilities) for every negotiation packages is given in Table 5 .

${ }^{3}$ Software VISUAL UTA available at: http://idss.cs.put.poznan.pl/site/visualuta.htm (date of access: 05.05.2015). 
TABLE 5.

The global utility functions and rankordering negotiation offers for all reference sets

\begin{tabular}{|c|c|c|c|c|c|c|c|c|c|}
\hline \multirow[t]{2}{*}{ Packages } & \multicolumn{3}{|c|}{ Criterion } & \multicolumn{2}{|c|}{$\begin{array}{c}\text { Reference Set } 1 \\
\left(\mathrm{RS}_{1}\right)\end{array}$} & \multicolumn{2}{|c|}{\begin{tabular}{|c|} 
Reference Set 2 \\
$\left(\mathrm{RS}_{2}\right)$
\end{tabular}} & \multicolumn{2}{|c|}{$\begin{array}{c}\text { Reference Set } 3 \\
\left(\mathrm{RS}_{3}\right)\end{array}$} \\
\hline & $\mathbf{f}_{1}$ & $f_{2}$ & $f_{3}$ & \begin{tabular}{|l|} 
Value \\
$\mathrm{U}(\mathrm{x})$ \\
\end{tabular} & Range & \begin{tabular}{|l|} 
Value \\
$\mathrm{U}(\mathrm{x})$ \\
\end{tabular} & Range & $\begin{array}{l}\text { Value } \\
\mathrm{U}(\mathrm{x}) \\
\end{array}$ & Range \\
\hline W1 & 20 & 3 & 21 & 1 & 1 & 1 & 1 & 1 & 1 \\
\hline W2 & 20 & 3 & 14 & 0,990 & 2 & 0,944 & 2 & 0,929 & 2 \\
\hline W3 & 20 & 3 & 3 & 0,667 & 15 & 0,889 & 6 & 0,643 & 10 \\
\hline W4 & 20 & 7 & 21 & 0,980 & 3 & 0,901 & 4 & 0,929 & 3 \\
\hline W5 & 20 & 7 & 14 & 0,970 & 4 & 0,846 & 8 & 0,857 & 4 \\
\hline W6 & 20 & 7 & 3 & 0,647 & 17 & 0,790 & 11 & 0,571 & 11 \\
\hline W7 & 20 & 14 & 21 & 0,955 & 5 & 0,778 & 12 & 0,839 & 5 \\
\hline W8 & 20 & 14 & 14 & 0,945 & 7 & 0,722 & 14 & 0,768 & 7 \\
\hline W9 & 20 & 14 & 3 & 0,622 & 21 & 0,667 & 16 & 0,482 & 18 \\
\hline W10 & 20 & 30 & 21 & 0,677 & 13 & 0,611 & 18 & 0,786 & 6 \\
\hline W11 & 20 & 30 & 14 & 0,667 & 14 & 0,556 & 21 & 0,714 & 8 \\
\hline W12 & 20 & 30 & 3 & 0,343 & 29 & 0,500 & 22 & 0,429 & 21 \\
\hline W13 & 30 & 3 & 21 & 0,945 & 6 & 0,944 & 3 & 0,643 & 9 \\
\hline W14 & 30 & 3 & 14 & 0,935 & 8 & 0,889 & 5 & 0,571 & 12 \\
\hline W15 & 30 & 3 & 3 & 0,612 & 25 & 0,833 & 9 & 0,286 & 29 \\
\hline W16 & 30 & 7 & 21 & 0,925 & 9 & 0,846 & 7 & 0,571 & 14 \\
\hline W17 & 30 & 7 & 14 & 0,915 & 10 & 0,79 & 10 & 0,5 & 16 \\
\hline W18 & 30 & 7 & 3 & 0,592 & 27 & 0,735 & 13 & 0,214 & 30 \\
\hline W19 & 30 & 14 & 21 & 0,900 & 11 & 0,722 & 15 & 0,482 & 19 \\
\hline W20 & 30 & 14 & 14 & 0,890 & 12 & 0,667 & 17 & 0,411 & 23 \\
\hline W21 & 30 & 14 & 3 & 0,567 & 28 & 0,611 & 19 & 0,125 & 33 \\
\hline W22 & 30 & 30 & 21 & 0,622 & 22 & 0,556 & 20 & 0,429 & 20 \\
\hline W23 & 30 & 30 & 14 & 0,612 & 23 & 0,500 & 23 & 0,357 & 25 \\
\hline W24 & 30 & 30 & 3 & 0,288 & 34 & 0,444 & 25 & 0,071 & 34 \\
\hline W25 & 40 & 3 & 21 & 0,657 & 16 & 0,500 & 24 & 0,571 & 13 \\
\hline W26 & 40 & 3 & 14 & 0,647 & 18 & 0,444 & 26 & 0,500 & 15 \\
\hline W27 & 40 & 3 & 3 & 0,323 & 32 & 0,389 & 28 & 0,214 & 31 \\
\hline W28 & 40 & 7 & 21 & 0,637 & 19 & 0,401 & 27 & 0,500 & 17 \\
\hline W29 & 40 & 7 & 14 & 0,627 & 20 & 0,346 & 29 & 0,429 & 22 \\
\hline W30 & 40 & 7 & 3 & 0,303 & 33 & 0,290 & 30 & 0,143 & 32 \\
\hline W31 & 40 & 14 & 21 & 0,612 & 24 & 0,278 & 31 & 0,411 & 24 \\
\hline W32 & 40 & 14 & 14 & 0,602 & 26 & 0,222 & 32 & 0,339 & 27 \\
\hline W33 & 40 & 14 & 3 & 0,278 & 35 & 0,167 & 33 & 0,054 & 35 \\
\hline W34 & 40 & 30 & 21 & 0,333 & 30 & 0,111 & 34 & 0,357 & 26 \\
\hline W35 & 40 & 30 & 14 & 0,323 & 31 & 0,056 & 35 & 0,286 & 28 \\
\hline \multirow[t]{2}{*}{ W36 } & 40 & 30 & 3 & 0 & 36 & 0 & 36 & 0 & 36 \\
\hline & \multicolumn{3}{|c|}{ Kendall Coefficient } & \multicolumn{2}{|c|}{1} & \multicolumn{2}{|c|}{1} & \\
\hline
\end{tabular}

Source: own elaboration using VisualUTA software. 
SCHEMA 2.

Rankordering negotiation packages from the set $\mathrm{X}$ and marginal utility function for the Reference Set 1
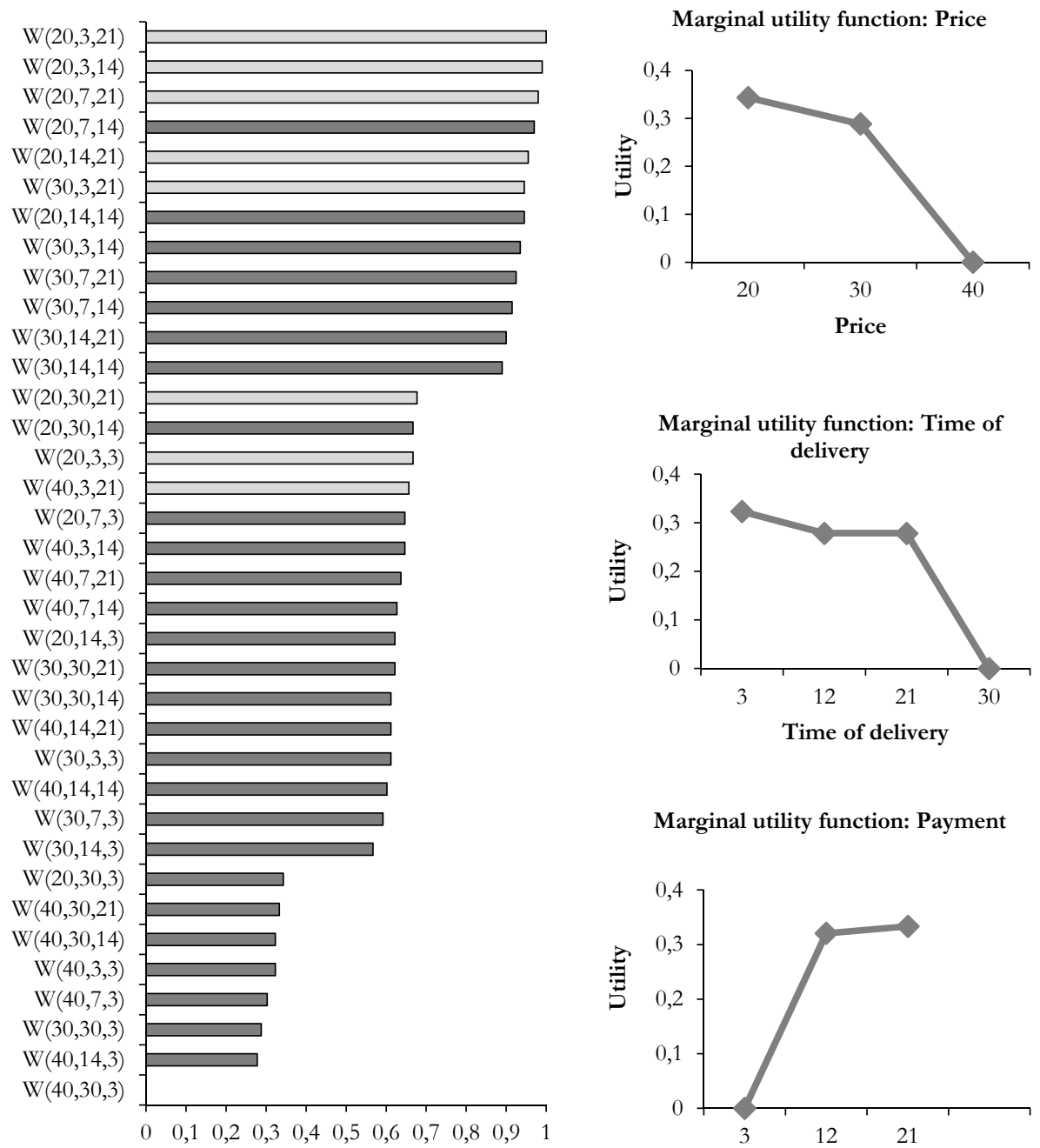

Marginal utility function: Payment

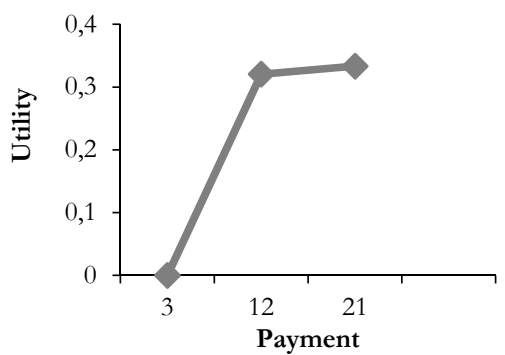

Source: own elaboration. 
SCHEMA 3.

Rankordering negotiation packages from the set $\mathrm{X}$ and marginal utility function for the Reference Set 2
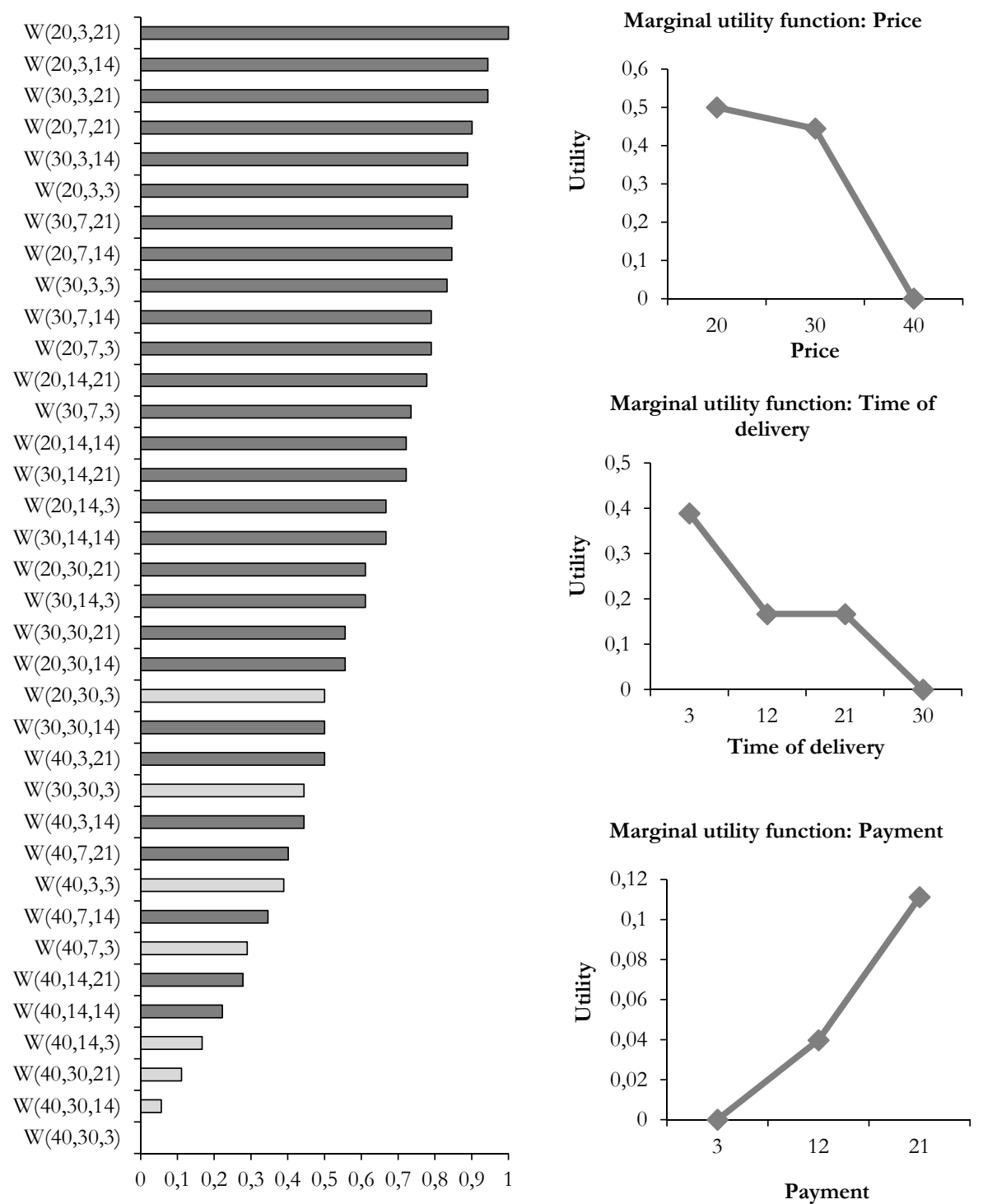

Source: own elaboration. 
SCHEMA 4.

Rankordering negotiation packages from the set $\mathrm{X}$ and marginal utility function for the Reference Set 3
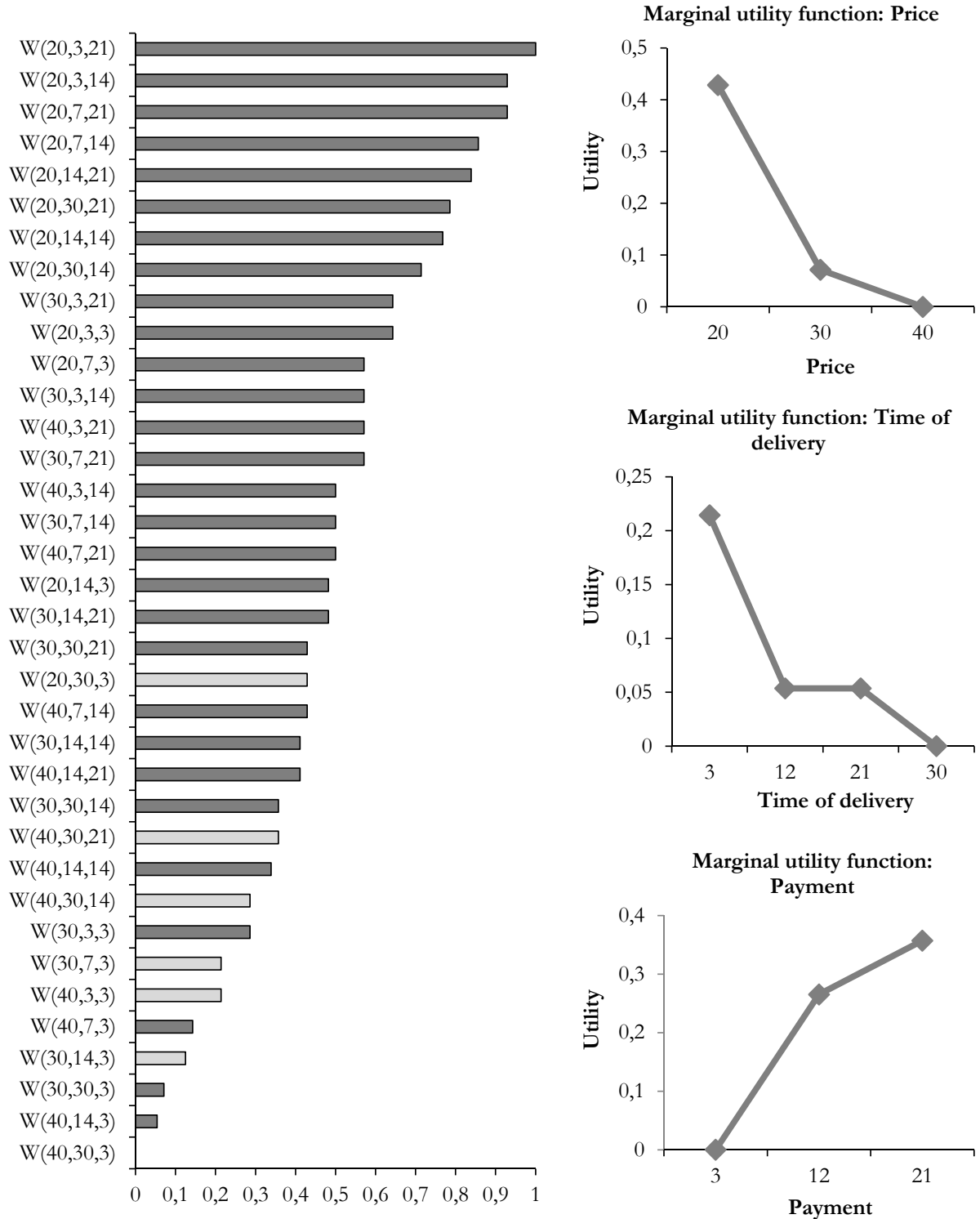

Source: own elaboration. 
The scores from Table 5 provide the negotiator with all relevant cardinal data sufficient to decide which of any two packages (offers) is better and by how much. They may also be used to perform the symmetric analysis to determine the fair solution for both parties during the mediation or arbitration process or to visualize the negotiation progress and the concession paths. However the negotiator have to take into account that the final ranking depends on reference set, so he could accept it or modify if necessary reference set.

Let us consider, for instance the packages $\mathrm{W}(20,3,3)$ and $\mathrm{W}(20,30,14)$ to show that offers can be quite different evaluated with respect to reference sets. In the scoring system 1 (based on Reference Set 1) those packages are fully comparable with 0,667 point. That mean the concession from 30 days to 3 days in time of delivery is equivalent to the concession from 3 days to 14 days in time of payment. In the scoring system 2 (based on Reference Set 2) offers $\mathrm{W}(20,3,3)$ is scored for 0,989 point and is more preferable than offer $\mathrm{W}(20,30,14)$ with 0,56 point. Finally, in the scoring system 3 (based on the Reference 3) offer $\mathrm{W}(20,3,3)$ with 0,643 point is less preferable than offer W $(20,30,14)$ with 0,714 point. The final ranking of the offers as well as their scores for considered reference sets are presented in Schema 3-6.

Let us assume now that during negotiation process negotiator can search and construct new packages and evaluate it using scoring function. The optimal scoring function should produce consistent ranking after new packages are added (or removed) and should not provide to rank reversal. This means that in the case of adding or removing new package the negotiator does not need to re-evaluate the previously evaluated packages, as well the score points of all packages are stable. It is worth nothing that the UTA technique allows introduced any package from negotiation space to set of packages new ones without rescoring other packages.

Summing up, a negotiator's evaluation of packages has been conducted by using holistic judgment on reference set of packages. The negotiation support by UTA algorithm takes into consideration the knowledge and preferential data provided by a negotiator. The whole implementation process is supported by UTA software due to its visualized environment that enables the interaction with the $\mathrm{DM}$ (mainly during the selection and ordering reference set, so construction of the additive value functions) and its practicability at solving the UTA model and graphically presenting the results.

\section{Conclusions}

In the paper a framework for the evaluation of negotiation offers based on holistic judgment and UTA methodology and UTA software have been proposed. We used the UTA method for ranking a finite set of negotiation offers, evaluated by the finite set of criteria The UTA method is based on indirect preference information and required from the negotiator a ranking of small subset of reference negotiation packages from the least preferable to the most preferable. The main goal of the UTA algorithm is the construction of utility function, according to ordinal regression approach, as compatible as possible with this reference ranking. The utility function compatible with the reference 
ranking is then used to the whole set of negotiation packages giving to each package a value that ranks them

The main key advantages of the UTA approach are the following:

1) The UTA approach can support the DM to improve her (his) knowledge about the decision making problem and her (his) way of preferring in order to allow a consistent decision to be achieved in evaluation negotiation offers.

2) The UTA technique allow for elicitation attractiveness of packages with procedure that transform ordinal information for reference set for cardinal information by a non-numerical pairwise comparison questioning. It is very useful approach especially were problem is poorly defined, in the context of qualitative issues which often appear in negotiation template, as well in the case of imprecise information.

3) The decision maker needs to rank the best to the worst of the alternatives of $\mathrm{R}$, by giving each alternative a rank. So, having a weak-order preference structure on a set of actions, the problem is to adjust additive value or utility functions based on multiple criteria, in such a way that the resulting structure would be as consistent as possible with the initial structure.

4) The holistic indirect evaluation and application UTA approach allow for: building the scoring system based on the preferential information defined for a predefined set of reference packages $P \subseteq X$, extending the scoring system for all feasible offers from $X$, taking into account either complete or incomplete preferential information defined for $P$, defining aspiration and reservation levels as the additional preferential information and eliminating the necessity of explicit definition of the issue weights.

5) The computation processes of determining the scoring function take into account the negotiation space of each issue as well the concepts of reservation and aspiration levels.

6) The UTA procedure makes possible to expand the negotiation template by introducing new package after the preference elicitation has been conducted (within the actual negotiation space) without modifying ranking preliminary estimated packages. That means that proposed scoring function produces consistent ranking after new packages are added (or removed) and does not provide to rank reversal.

The main advantages of VISUAL UTA software are that the procedure is straightforward and friendly for decision maker and allow for useful visualizations results. The disadvantages of the UTA technique is fact that the UTA procedure depend on the reference set, so it may produced not satisfactory scoring functions. Moreover, in UTA, the DM's overall preferences are expressed on a set $R$ of real or fictitious reference packages, in the form of a ranking or pairwise comparison of these packages, so can used only partially indirect preference information. One of the solution in such case is using the other techniques from the UTA family, for instance GRIP procedure which adopts all features of UTA approach and takes additional information into account, in the form of comparisons of intensities of preference between actions. These comparisons 
may be expressed comprehensively (on all criteria) and/or partially (on each criterion) [Figueira et al. 2009; Greco et al. 2008; Kadziński et al. 2012].

The future work will focus on verifying usefulness of holistic judgment and UTA approach in negotiation experiments taking into account different recommendation reference sets as well testify other multi criteria technique based on holistic judgment and indirect preference information (such as GRIP, MARS, among others) for evaluation negotiation packages.

\section{Bibliography}

Bana e Costa C., Vansnick J.-C., 1999, The MACBETH approach: Basic ideas, software, and an application, [in:] Advances in Decision Analysis, N. Meskens, M. Roubens (eds.), Springer.

Brzostowski J., Wachowicz T., Roszkowska E., 2012a, Using an Analytic Hierarchy Process to Develop a Scoring System for a set of Continuous Feasible Alternatives in Negotiation, "Operations Research and Decisions", No. 4.

Brzostowski J., Roszkowska E., Wachowicz T., 2012b, Supporting Negotiation by MultiCriteria Decision-Making Methods, "Optimum. Studia Ekonomiczne", nr 5 (59).

Figueira J., Greco S., Słowiński R., 2009, Building a set of additive value functions representing a reference preorder and intensities of preference: GRIP method, "European Journal of Operational Research", 195.

Górecka D., Roszkowska E., Wachowicz D., 2014, MARS - a bybrid of ZAPROS and $M A C B E T H$ for verbal evaluation of the negotiation template, [in:] Group Decision and Negotiation 2014, GDN 2014, Proceedings of the Joint International Conference of the INFORMS GDN Section and the EURO Working Group on DSS , P. Zaraté, G. Camilleri, D. Kamissoko, F. Amblard (eds.), Toulouse University, France.

Górecka D., Roszkowska E., Wachowicz T., 2016, The MARS Appoach in the Verbal and Holistic Evaluation of the Negotiation Template, Group Decision and Negotiaion, DOI:10.1007/s10726-016-947592016.

Greco S., Mousseau V., Slowiński R., 2008, Ordinal regression revisited: Multiple criteria ranking using a set of additive value functions, "European Journal of Operational Research", 191.

Jacquet-Lagrèze E., Siskos J., 1978, Une méthode de construction de fonctions d' utilité additives explicatives d' une préférence globale, "Cahier du LAMSADE", 16, Université de ParisDauphine.

Jacquet-Lagrèze E., Siskos Y., 1982, Assessing a set of additive utility functions for multicriteria decision making: The UTA method, "European Journal of Operational Research", 10 (2).

Jacquet-Lagrèze E., Siskos Y., 2001, Preference disaggregation: 20 years of MCD $A$ experience, "European Journal of Operational Research", 130 (2).

Ishizaka A., Nemery P., 2013, Multi-Criteria Decision Analysis. Methods and Software, Wiley, United Kindgdom

Kadziński M., Greco S., Słowiński R, 2012, Selection of a representative value function in robust multiple criteria ranking, and choice, "European Journal of Operational Research", 217.

Kersten G. E., Lai H., 2007, Negotiation support and e-negotiation systems: an overview, "Group Decis Negot", 16(6). 
Kersten G. E, Noronha S. J., 1999, WWW-based negotiation support: design, implementation, and use, "Decis Support Sys", 25(2).

Larichev O. I., Moshkovich H. M., 1995, ZAPROS-LM - A method and system for ordering multiattribute alternatives, "Eur J Oper Res", 82(3).

Larichev O. I., Moshkovich H. M., 1997, Verbal decision analysis for unstructured problems, Kluwer Academic Publishers, Boston.

Moshkovich H. M., Mechitov A. I., Olson D. L., 2005, Verbal Decision Analysis, [in:] Multiple Criteria Decision Analysis: State of the Art Surveys, J. Figueira, S. Greco, M. Ehrgott (eds.), Springer, New York.

Mustajoki J., Hamalainen R. P., 2000, Web-HIPRE: Global decision support by value tree and AHP analysis, "INFOR J", 38(3).

Raiffa H., 1982, The Art and Science of Negotiation, The Belknap Press of Harvard University Press, Cambridge (MA).

Raiffa H., Richardson J., Metcalfe D., 2002, Negotiation Analysis, The Belknap Press of Harvard University Press, Cambridge.

Roszkowska E., Brzostowski J., Wachowicz T., 2014a, Supporting Ill-Structured Negotiation Problems, [in:] Human-Centric Decision-Making Models for Social Sciences, P. Guo, W. Pedrycz (eds.) Springer, London.

Roszkowska E., Wachowicz T., 2014, The Multi-Criteria Negotiation Analysis Based on the Membership Function, "Studies in Logic, Grammar and Rhetoric", Mechanisms and Methods of Decision Making (ed. E. Roszkowska), 37(50).

Roszkowska E., Wachowicz T., 2015a, Application of fuzzy TOPSIS to scoring the negotiation offers in ill-structured negotiation problems, "Eur J Oper Res", 242(3).

Roszkowska E., Wachowicz T., 2015b, Holistic evaluation of the negotiation template - comparing MARS and GRIP approaches, [in:] The 15th International Conference on Group Decision and Negotiation Letters, B. Kamiński, G. Kersten, P. P. Szufel, M. Jakubczyk, T. Wachowicz (eds.), Warsaw School of Economics Press, Warsaw.

Roszkowska E., Wachowicz T., 2016, Negocjacje. Analiza i wspomaganie decyzji, Wolter Kluwer, Warszawa

Saaty T. L., 1980, The Analytic Hierarchy Process, McGraw Hill, New York, N.Y.

Siskos Y., Grigoroudis E., Matsatsinis N. F., 2005, UTA methods. Multiple criteria decision analysis: State of the art surveys, Springer.

Salo A., Hamalainen R. P., 2010, Multicriteria Decision Analysis in Group Decision Processes, [in:] Handbook of Group Decision and Negotiation, D. M. Kilgour, C. Eden (eds.), Springer, New York.

Schoop M., Jertila A., List T., 2003, Negoisst: a negotiation support system for electronic business-to-business negotiations in e-commerce, "Data \& Knowledge Engineering", 47(3).

Siskos Y., Grigoroudis E., Matsatsinis N. F., 2005, UTA methods. Multiple criteria decision analysis: State of the art surveys, Springer.

Wachowicz T., Błaszczyk P., 2013, TOPSIS based approach to scoring negotiating offers in negotiation support systems, "Group Decision and Negotiation", 22.

Wachowicz T., Brzostowski J., Roszkowska E., 2012, Reference Points-Based Methods in Supporting the Evaluation of Negotiation Offers, "Operations Research and Decisions", No. 4. 